This item was submitted to Loughborough's Research Repository by the author.

Items in Figshare are protected by copyright, with all rights reserved, unless otherwise indicated.

\title{
Thermal stability of high temperature Pb-free solder interconnect characterised by in-situ electron microscopy
}

PLEASE CITE THE PUBLISHED VERSION

https://doi.org/10.1109/ESTC.2018.8546440

PUBLISHER

(C) IEEE

VERSION

AM (Accepted Manuscript)

LICENCE

CC BY-NC-ND 4.0

REPOSITORY RECORD

Zhou, Zhaoxia, Li Liu, and Changqing Liu. 2019. "Thermal Stability of High Temperature Pb-free Solder Interconnect Characterised by In-situ Electron Microscopy”. figshare. https://hdl.handle.net/2134/36948. 


\section{Thermal stability of high temperature Pb-free solder interconnect characterised by in-situ electron microscopy}

\author{
Zhaoxia Zhou* \\ Loughborough Materials Characterisation \\ Centre, Department of Materials, \\ Loughborough University \\ Loughborough, UK, LE11 3TU \\ * Corresponding author: \\ Z.Zhou@lboro.ac.uk
}

\author{
Li Liu \\ Wolfson School of Mechanical, \\ Electrical, Manufacutring Engineering \\ Loughborough University, \\ Loughborough, UK, LE11 3TU \\ Current address: \\ School of Materials Science and Engineering, \\ Wuhan University of Technology, \\ Wuhan, China, 430070. \\ ..liu@whut.edu.cn.
}

\author{
Changqing Liu \\ Wolfson School of Mechanical, \\ Electrical, Manufacutring Engineering \\ Loughborough University \\ Loughborough, UK, LE11 3TU \\ C.Liu@lboro.ac.uk
}

\begin{abstract}
The present investigation aimed to use in-situ heating experiment in a transmission electron microscope (TEM) to live characterize the thermal stability of a $\mathrm{Cu} / \mathrm{Ni}-\mathrm{W}-\mathrm{P}$ interlayer/ZnAl solder interconnect. It demonstrated the TEM was able to detect live intermetallic compounds (IMCs) growth during heating. In addition, stress building up was evidenced by the progressive evolving of the dislocations at the interface between $\mathrm{Ni}$ W-P interlayer and the $\mathrm{ZnAl}$ Solder. However, due to the $\mu \mathrm{m}$ to nm scale of specimens' dimensions required for electron microscopy, the sample preparation and data interpretation remains a challenge.
\end{abstract}

Keywords - Thermal stability, high temperature $\mathrm{Pb}$-free solder, Zn-Al solder, interconnect, in-situ electron microscopy

\section{INTRODUCTION}

To maximize the potential of wide-band-gap (WBG) semiconductor devices in power electronics, there are manufacturing challenges as well as reliability requirements. High-temperature joining methods are one of them to enable the necessary electrical, thermal and mechanical interconnections, hence robust assemble of power electronic modules manufacturing reliable components. Solder attachment with high-melting-point, $\mathrm{Pb}$-rich solders (e.g. Pb-5Sn with $\mathrm{T}_{\mathrm{m}} \sim 305^{\circ} \mathrm{C}$ ) has been widely established $[1,2]$. However, in response to the European Union directive Restriction of Hazardous Materials (RoHS), restrictions on the use of $\mathrm{Pb}$ will inevitably become more stringent over time. Among the $\mathrm{Pb}$-free high temperature solders including Au-based solder, $\mathrm{Bi}-\mathrm{Ag}$ solder, Zn-based solder and so on, the $\mathrm{Zn}-\mathrm{Al}$ solder shows great potential due to its low-cost, high melting point, excellent mechanical property, good thermal and electrical conductivity $[3,4]$. However, rapid interfacial reactions between $\mathrm{Zn}-\mathrm{Al}$ solders and $\mathrm{Cu}$ substrates significantly deteriorate the reliability of the solder interconnects [5]. Thus, novel metallisation such as electroless Ni based interlayers (Ni-W-P, Ni-P) were applied [6] as a diffusion barrier to resist the interfacial interaction and subsequent diffusion.

This work is supported by UK EPSRC Underpinning Power Electronics 2017: Heterogeneous Integration (EP/R004501/1), 2017-2020.
In the meantime, interconnects bonding reliability prediction is of great interest to many areas of power electronics. It is widely accepted that the interfacial reaction layers at solder/substrate interfaces are crucial for the reliability of power electronics, which demands fundamental understanding on their formation and evolution mechanism [7, 8]. Conventionally, works have been carried out on the fixed state of the solder joints under different thermal conditions, followed by subsequent examination using scanning electron microscopy (SEM) or transmission electron microscopy (TEM) techniques $[9,10]$, i.e. post-mortem examination or ex-situ method.

With the high integration in component design (i.e. small size scale of the interconnects) and the recent fast advance of the electron microscopy techniques, we propose to utilize the in-situ electron microscopy techniques to evaluate interconnects reliability. The in-situ electron microscopy offers clear advantages: 1) visualisation at micron to nanometer resolution of the thinnest layers in an interconnect having several interfaces; 2) applying simultaneous stimuli of heating/cooling and/or biasing while observing live degradation [11]. In this work, using $\mathrm{Zn}-5 \mathrm{Al}$ solder and Ni-W-P under bump metallization layer on $\mathrm{Cu}$ substrate, in-situ heating test was performed in a FEI Tecnai F20 transmission electron microscope (TEM). The conventional ex-situ characterisation would only have chance to record the microstructures of the starting point and the final heat-treatment. All the intermediate stages would have been missed, hence the conclusions could be hypothesis.

\section{EXPERIMETAL PROCEDURES}

\section{A. Interconnects preparation}

The interconnect was prepared in 3 steps: (i) an electroless Ni-W-P ternary alloy was produced on polycrystalline copper substrates; (ii) Zn-5Al solder pellets (weight: approximately $0.15 \mathrm{~g}$, melting point: $382^{\circ} \mathrm{C}$ ) were then placed on $\mathrm{Ni}-\mathrm{W}-\mathrm{P}$ plated $\mathrm{Cu}$ substrates; (iii) reflow was conducted at $450^{\circ} \mathrm{C}$ on a 
hotplate attached to a temperature control unit. Details of the electroless plating and reflow profile can be found in a previous paper [6].

\section{B. Specimen preparation and electron microscopy}

The interconnect with a reflow time of 1 minute was selected. Standard metallography specimen was prepared as the following --- a cross section block was cold mounted, ground and polished using diamond paste followed by colloidal silica. A lamella cross section of the interconnect was lifted out perpendicular to the interfaces using a FEI focused ion beam (FIB) Nova Nanolab 600 and transferred to a DENSsolutions ${ }^{\circledR}$ micro-electromechanical systems (MEMS)-based heating chip (mounted on the custom SEM stub with $45^{\circ}$ faces), as well as final thinning of the lamella sample for the purpose of in-situ TEM investigation. The FIB instrument comprises a $30 \mathrm{kV}$ electron column for scanning electron microscopy (SEM) and a $30 \mathrm{kV}$ ion column $\left(\mathrm{Ga}^{+}\right)$, mounted at $52^{\circ}$ to the electron column, which allows micron scale fabrication (e.g. digging, welding, cutting and depositing) on the sample. The system is equipped with a micro-manipulator and a gas injector for the in-situ deposition of Pt. Details of the preparation can be found elsewhere [11, 12].

The final thinned lamella was mounted onto the MEMS heating chip, which is ready to be loaded onto a TEM sample holder and inserted to a TEM and perform heating experiment live inside the TEM. A FEI Tecnai F20 field emission gun scanning transmission electron microscope (FEG-STEM) was employed to perform the experiment. The TEM was operated at $200 \mathrm{kV}$, equipped with a Fischione high angle annular dark field (HAADF) detector and a Gatan bright field (BF) detector to record STEM images. In addition, elemental mapping was conducted using the attached Oxford Instruments X-max80 TLE windowless X-ray detector for energy dispersive X-ray spectroscopy (EDS) analysis. The heating profile was shown in Fig. 1.

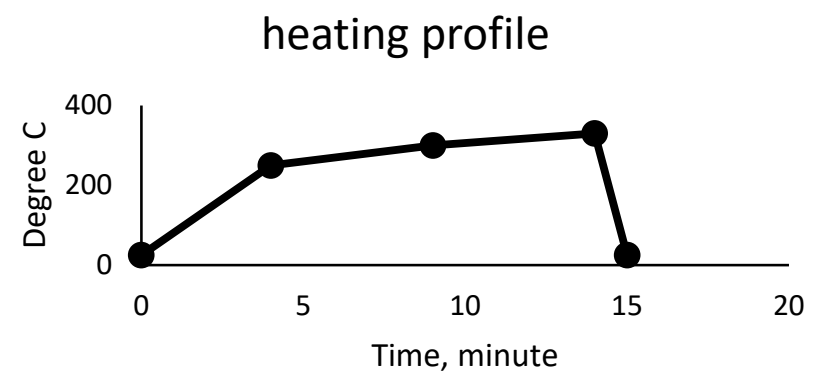

Fig. 1. Heating profile of the in-situ experiment.

\section{RESULTS AND DISCUSSION}

Figure 2a shows a bright field TEM image highlighting the through holes on the MEMS heating chip (DENSsolutions). Figure 2b shows the lamella of interconnect cross section lying on top of a hole. Layers of the interconnect can be seen clearly. It was recommended to select one of holes at the centre of the chip for the best accuracy of temperature control although the temperature error is $<5 \%$ [13]. Note the TEM lamella has an area of approximately $10 \mu \mathrm{m} \times 5 \mu \mathrm{m}$ (length $\times$ width). The thickness of the lamella is $\sim 150 \mathrm{~nm}$ at the two sides, with the middle region of $100 \mathrm{~nm}$ to allow the best electron transparency, which was aimed to be aligned approximately across the hole, as shown in Fig. 2b.
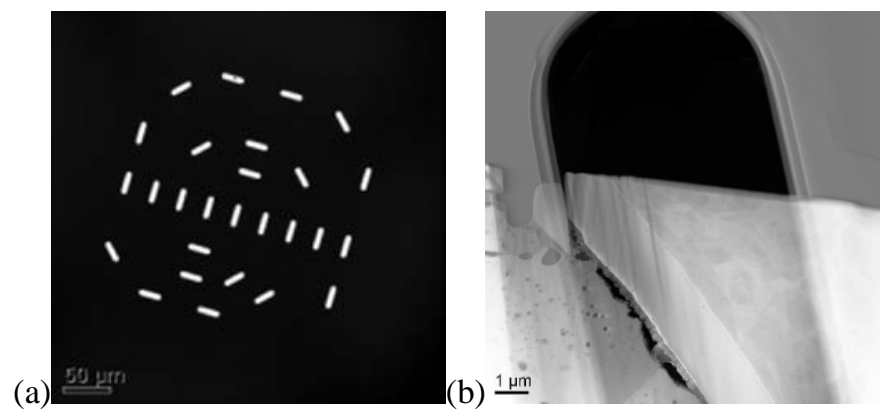

Fig. 2a) Centre holes on the MEMS heating chip; b) the lamella TEM specimen which contains the interconnect interfaces lying across a hole.
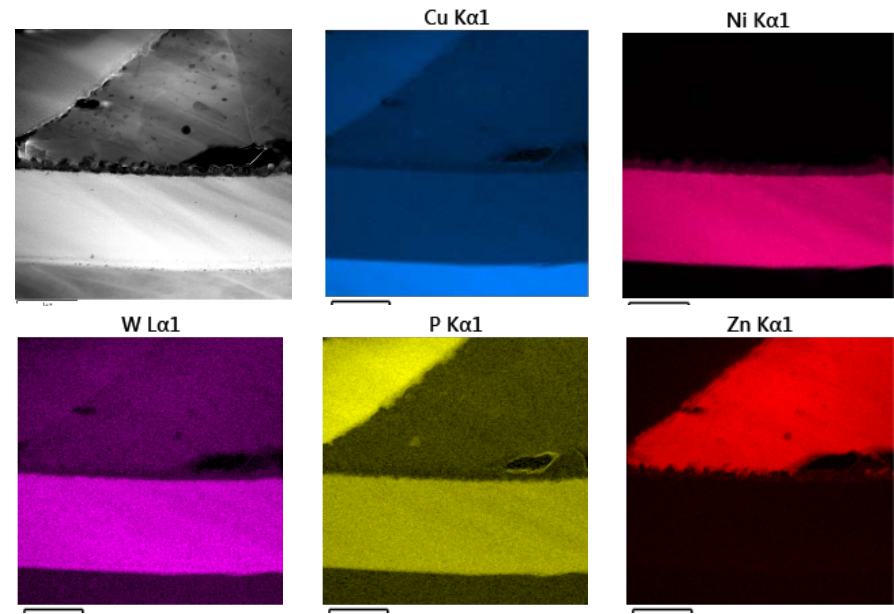

Al $K \alpha$
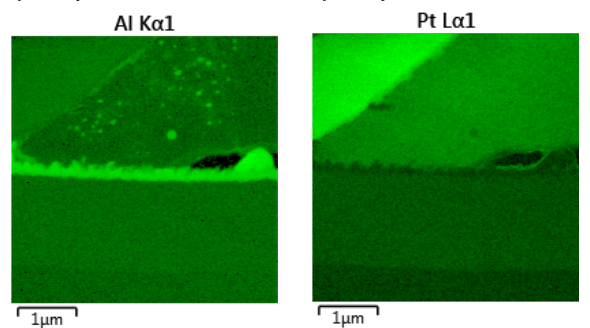

Fig. 3. STEM/HAADF image of the interconnect and the corresponding EDS elemental maps.

Figure 3 shows the image of the cross-sectional interconnect and the chemical maps of the layers. The interconnect includes the $\mathrm{Cu}$ substrate, the electroless plated interlayer of $\mathrm{Ni}-\mathrm{W}-\mathrm{P}$ (1.8 $\mu \mathrm{m}$ thick), the $\mathrm{Zn}-\mathrm{Al}$ solder on top of the Ni-W-P interlayer, as indicated by the elemental maps respectively. Note the top left triangle is $\mathrm{Pt}$, which is a layer deposited during FIB specimen preparation to preserve the outermost surface and facilitate uniform thinning of the specimen. The $\mathrm{P} \mathrm{K \alpha}$ is $2.013 \mathrm{keV}$, overlapping with $\mathrm{Pt} \mathrm{M} \alpha$ of $2.049 \mathrm{keV}$, thus the $\mathrm{Pt}$ is also highlighted in $\mathrm{P}$ map. There is a thin layer of IMCs rich in $\mathrm{Ni}$ and $\mathrm{Al}$ already present at the interface of $\mathrm{Zn}-\mathrm{Al}$ and Ni-W-P. This layer is due to the initial formation after reflow for 1 minute 
during the preparation of the $\mathrm{Zn}-\mathrm{Al}$ interconnect. Thus, the interface is free of oxidation and allows the interfacial diffusion and reaction between the solder and the substrate during the subsequent in-situ heating in the TEM. Majority of the interface was sealed by the IMCs though some area did show voids as towards to the right end of this image.
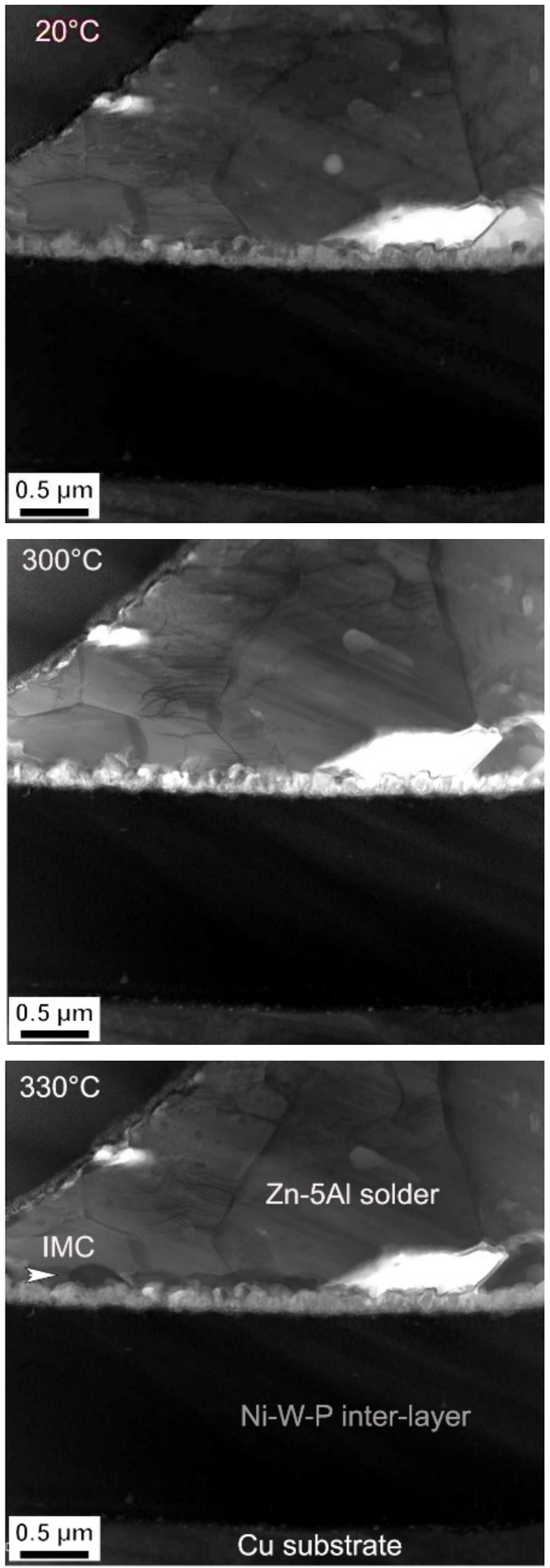

Fig. 4. STEM/BF images of the microstructure of the interconnects recorded at representative temperatures with major transition of microstructures.
Figure 4 shows images recorded at three temperatures: start room temperature $\left(20^{\circ} \mathrm{C}\right), 300^{\circ} \mathrm{C}$ and $330^{\circ} \mathrm{C}$ during the in-situ heating experiment in the TEM. They represent major microstructure transition stages. No obvious change was detected before $300^{\circ} \mathrm{C}$ in terms of the microstructures of the interfaces based on the many frames recorded every $\sim 5$ seconds. However, comparing images at $20^{\circ} \mathrm{C}$ and $300^{\circ} \mathrm{C}$, one can notice the dislocations (the dark lines in the middle grain) moving up away from interface. This indicates stress starting to build up at the interface. During imaging recording of the in-situ experiment, the specimen holder and TEM experimental settings were maintained unchanged to the best of possibility. The fact that the contrast of the adjacent grains and grain boundaries remained suggests that the change was not caused by mechanical deformation at the whole lamella scale (i.e. not caused by bending between the lamella and heating chip), but local within the specimen at the solder/interlayer interface. The reason other grains didn't show dislocations but this one showed is mainly because this grain happened to be situated at the two-beam diffraction condition to allow best visibility of dislocations [14], others didn't satisfy the condition, hence dislocations invisible. Soon after this, an additional IMC layer spread at the interface as shown in the image recorded at $330^{\circ} \mathrm{C}$ (arrowed). The void remained largely unchanged so far at this stage.

\section{CONCLUDING REMARKS}

The results showed that live growth of IMCs between the $\mathrm{ZnAl}$ solder and the Ni-W-P under bump metallisation layer, as well as the strain induced during the heating as evidenced by the progressive dislocations evolution during an in-situ heating experiment performed in a TEM. It demonstrated that in-situ TEM could be a powerful tool in simulating reliability and thermal stability and monitoring the microstructural degradation. However, due to the small dimension of the specimen that can be examined and the challenging sample preparation, more research is required to realise the true potential in the future.

\section{ACKNOWLEDGMENT}

The authors acknowledge use of the facilities and the assistance of Mr. Scott Doak in the Loughborough Materials Characterization Centre for constant assistance with the FIB sample preparation. Dr. Ali Abbas, Loughborough University, Drs Hugo Perez Garza, Ryan Ramsay and Qiang Xu, DENSsolutions, Delft, The Netherlands and Dr. David Westmoreland, LOT quantum design ltd are also acknowledged for supplying the TEM wildfire holder and provide great support on the experiment.

\section{References}

[1] H. Wang, X. Ma, F. Gao, Y. Qian, "Sn concentration on the reactive wetting of high- $\mathrm{Pb}$ solder on $\mathrm{Cu}$ substrate", Mater. Chem. Phys., 99(2006): pp. 202-205. 
[2] V. Chidambaram , J. Hattel, J. Hald, "High-temperature lead-free solder alternatives”, Microelectron. Eng., 88(2011), pp. 981-989.

[3] A. Haque, B.H. Lim, A.S.M.A. Haseeb, H.H. Masjuki, "Die attach properties of $\mathrm{Zn}-\mathrm{Al}-\mathrm{Mg}-\mathrm{Ga}$ based high-temperature lead-free solder on Cu lead-frame”, J. Mater. Sci. Mater. Electron., 23 (2012), pp. 115-123.

[4] T. Gancarz, J. Pstruś, P. Fima, S. Mosińska, "Thermal properties and wetting behavior of high temperature Zn-Al-In solders”, J. Mater. Eng. Perform., 21 (2012), pp. 599-605.

[5] Y. Takaku, L. Felicia, I. Ohnuma, R. Kainuma, K. Ishida, "Interfacial reaction between $\mathrm{Cu}$ substrates and $\mathrm{Zn}$ - $\mathrm{Al}$ base high-temperature $\mathrm{Pb}$-Free solders”, J. Electron. Mater., 37 (2008), pp. 314-323.

[6] L. Liu, Z. Chen, Z. Zhou, G. Chen, F. Wu, C. Liu, "Diffusion barrier property of electroless Ni-W-P coating in hightemperature $\mathrm{Zn}-5 \mathrm{Al} / \mathrm{Cu}$ solder interconnects”, J. Alloys Compd., 722(2017), pp. 746-752.

[7] C.Y. Ho, M.T. Tsai, J.G. Duh, J.W. Lee, "Bump height confinement governed solder alloy hardening in $\mathrm{Cu} / \mathrm{SnAg} / \mathrm{Ni}$ and $\mathrm{Cu} / \mathrm{SnAgCu} / \mathrm{Ni}$ joint assemblies”, J. Alloys Compd., 600(2014), pp. 199-203.

[8] J. Berthea, F. Hodaj, N. Hotellier, J. Charbonnier, "Effect of intermetallic compound thickness on shear strength of $25 \mu \mathrm{m}$ diameter Cu-pillars", Intermetallics., 51(2014), pp. 37-47.
[9] C.E. Ho, C.C. Wang, M.A. Raham, Y.C. Lin, "Field-emission transmission electron microscopy study of the reaction sequence between Sn-Ag-Cu alloy and an amorphous $\operatorname{Pd}(\mathrm{P})$ thin film in microelectronic packaging”, Thin Solid Films., 529(2013), pp. 369-373.

[10] K. Chen, C. Liu, D.C. Whalley, D.A. Hutt, J.F. Li, S.H. Mannan, "A comparative study of the interfacial reaction between electroless Ni-P coatings and molten tin”, Acta Mater., 56(2008), pp. 5668-5676.

[11] T.P. Almeida, D. McGrouther, Y. Pivak, H.H.P. Garza and et al., "Preparation of high-quality planar FeRh thin films for in-situ TEM investigations", in proceedings of the $8^{\text {th }}$. Joint European Magnetic Symposia Coference, Journal of Physics: Conf. Series, 903(2017): 012022.

[12] M. Canavan, D. Daly, A. Rummel, E.K. McCarthy, C. McAuley, V. Nicolosi, "Novel in-situ lamella fabrication technique for in-situ TEM", Ultramicroscopy., 190(2018), pp. 21-29.

[13] DENSsolutions wildfire datasheet 2015.

[14] D.B. Willams and C.B. Carter, Transmission Electron Microscopy: A Textbook for Materials Science, Springer, 2009. 